\title{
Biosynthesis of Beta vulgaris mediated ZnO Nanoparticles and their Anti-bacterial, Anti-fungal, Anti-diabetic and Anti-cancer Activities
}

\author{
FEMINA. $F^{\star}$, H. ASIA THABASSOOM, S. AUXILIA RUBY and J. FELICITA FLORENCE \\ Holy Cross College (Autonomous), Affiliated to Bharathidasan University, Tiruchirappalli-620002, \\ Tamilnadu, India.
}

http://dx.doi.org/10.13005/ojc/370420

(Received: May 07, 2021; Accepted: July 10, 2021)

\begin{abstract}
Plant extract mediated metal or metal oxide nanoparticles is a promising alternate to the chemical and physical methods. Application of nanoparticles in various fields get increased widely due to their properties. Current study involves the eco-friendly method of synthesis and pharmacological applications of zinc oxide nanoparticles (ZnO-NPs) using the aqueous beetroot (Beta vulgaris) extract. Aqueous Beta vulgaris extract has multiple bio-active phytochemicals especially antioxidants like anthocyanins and betacyanins, also reported a rich source of minerals. Synthesized ZnONPs were characterized with the aid of UV-Vis spectroscopy, FTIR, SEM, XRD and EDX. Antibacterial results suggests that, Beta vulgaris mediated ZnONPs possessthe maximum zone of inhibition against Escherichia coli then Staphylococcus aureus. On anti-fungal activity synthesized ZnONPS revealed greater inhibitory effect against Candida albicans fungi than the Aspergillus flavus. Synthesized ZnONPs exhibits the noticeable pharmacological activities against the anti-diabetic and anti-cancer activities (MCF-7 cell line, $I_{50}=35.4 \mu \mathrm{g} / \mathrm{mL}$ ). This study has suggested an effective replacement for the hazardous chemical methods and lead to a cost-effective, environmentally-friendly method which can also be used as an antimicrobial, anti-diabetic and anti-cancer agents.
\end{abstract}

Keywords: Beta vulgaris, Phytochemical analysis, Zinc nanoparticles, Anti-bacterial, Anti-fungal activity, Anti-diabetic activity, Anti-cancer activity.

\section{INTRODUCTION}

Nanotechnology is the, multidisciplinary of all scientific fields which undergoing explosive development in science. Nanotechnology is one of the most revolutionary paths for the active researchers. Nanotechnology/nanoscience involves the synthesis, characterization and to manipulate the particle size of $1-100 \mathrm{~nm}$ range, providing to the path of numerous application which includes, sensors, communication, cosmetics, drug delivery, dye degradation, electronics, pharmaceutical, health care, food chemistry, chemical industries, water remediation and agriculture. The modification of material size results in achieving novel physiochemical properties and biomedical applications. $^{1}$

The metal and metal oxide nanoparticles have the countless interest owing its distinctive

This is an Open Access article licensed under a Creative Commons license: Attribution 4.0 International (CC- BY). Published by Oriental Scientific Publishing Company @ 2018

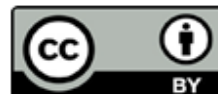


feature of applications in the various fields. Zinc oxide nanoparticles (ZnONPs) synthesis are regarded as safe material to human beings and animals and hence attracted exciting research like antioxidant activity $^{2}$, UV sensors ${ }^{3}$, drug delivery ${ }^{4}$, biosensors ${ }^{5}$ and environmental remediation ${ }^{6}$.Moreover ZnONPs have been viable solution to stop infectious diseases due to the antibacterial property ${ }^{7}$.

Based on the literature, biological synthesis of $\mathrm{ZnO}$ nanoparticles from plant extracts are more stable biocompatible in comparing with those produced by physical and chemical method ${ }^{8}$. Unique feature of green synthesized nanomaterial is the selectivity and formation of different shapes and morphologies in accordance to various biological source used with enhanced stability. Biosynthesis of ZnONPs by using numerous plant extracts including Calotropis gigantean leaf extract ${ }^{9}$, Ixora coccinea leaf extract ${ }^{10}$, Hibiscus rosa-sinesis ${ }^{11}$, Cassia auriculata ${ }^{12}$, Argemone maxicana leaf extract ${ }^{13}$ and Lycopersicon esculentum (tomato) peel ${ }^{14}$ which develop the antimicrobial, antifungal and antioxidant properties in the nanoparticle.

Present work deals with green synthetic strategy to prepare ZnONPs from Beta vulgaris (Beetroot) extract commonly known as Beet greens and belongs to the family Amaranthaceous. Beet root is a pop vegetable and can be grown easily with good yield in a short span of time. Beetroot i.e. Beta vulgaris consists of numerous pharmacologically active phyto-chemicals including the betalains like betaxanthins and betacyanins followed by polyphenolics, flavonoids, in addition to inorganic nitrates and rich source of micro and macro minerals were reported $^{15,16}$. Betanin so called beetroot red is most common pigment in beetroots is responsible for their strong color. As a nutritious rich source, the beet root hold the pharmacological actions such as anti-oxidant, anti-inflammatory effects ${ }^{17}$, anti-carcinogenic, antimicrobial, anti-diabetic, antibacterial and wound healing properties ${ }^{18,19}$.

Present work aimed to synthesis the ecofriendly Beta vulgaris mediated $\mathrm{ZnO}$ nanoparticles and its characterizations by UV-Vis, FT-IR, SEM, XRD and EDAX. In this green synthesis of ZnONPs, the beetroot extract can act as a capping and stabilizing agents which has already owe pharmacological activities and it may improves the pharmacological effects of formed ZnONPS. Antibacterial, anti-diabetic and anti-cancer activities of Beta vulgaris mediated $\mathrm{ZnO}$ nanoparticles will be studied in this research.

\section{MATERIALS AND METHODS}

\section{Materials and reagents}

Zinc acetate di hydrate, $\mathrm{HCl}$, D.D water and $\mathrm{NaOH}$ were purchased from Eswarre scientific \& Co, Tiruchirappalli. Beta vulgaris were purchased from local markets, and all the precursor and reducing reagents are prepared by using the double distilled (D.D) water.

\section{Methods \\ Preparation of Beta vulgaris extract}

The Beta vulgaris was washed several times with water to remove dust particles. $250 \mathrm{gm}$ of cleaned Beta vulgaris were chopped into fine pieces and transfer into $500 \mathrm{~mL}$ beaker. Then, double distilled water added and boiled at $50^{\circ} \mathrm{C}$ at 60 min until the color of the aqueous solution turned into deep red color. Obtained extract was cooled and then filtered using normal paper followed by Whatmann No-1 filter paper. Final filtrate was stored in a refrigerator for further qualitative analysis and ZnONps synthesis.

\section{Preparation of ZnONPs}

For ZnONPs synthesis, $50 \mathrm{~mL}$ of $0.01 \mathrm{M}$ Zinc acetate dihydrate solution $\left(\mathrm{Zn}\left[\mathrm{CH}_{3} \mathrm{COO}_{2}\right.\right.$. $2 \mathrm{H}_{2} \mathrm{O}$ ) was taken and boiled at $30-40^{\circ} \mathrm{C}$ on heating mandle. $2 \mathrm{~mL}$ of Beta vulgar is extract was added to the solution and the mixture is then stirred using magnetic stirrer for $2 \mathrm{~h}\left(\right.$ at $60^{\circ} \mathrm{C}$ ) to get deep pale yellow colored solution. Final deposited particles were collected and washed with double distilled water and followed by heated in a hot air furnace at $150^{\circ} \mathrm{C}$ for $18 \mathrm{~h}$ for the complete conversion of zinc hydroxide to zinc oxide. Obtained dirty white powder was grinded into fine powder using a mortar and pestle then, took for characterization and other pharmacological applications. In the same way different ratio of zinc acetate and additive Beta vulgaris aqueous extract were tried along with that the effect of $\mathrm{pH}$ was studied between 5 to $10 \mathrm{pH}$ in the synthesis. Using hydrochloric acid and sodium hydroxide the $\mathrm{pH}$ of the medium i.e. 5 to $10 \mathrm{pH}$ was maintained throughout the work. 


\section{Characterization of ZnONPs}

Synthesized Beta vulgaris mediated ZnONPs nanoparticles were characterized with the help of UV-Visible spectrometer, FTIR, SEM, XRD and $E D X^{20,21}$. FT-IR helped to identify the probable functional groups which is involved in the reduction of $\mathrm{Zn}^{2+}$ to Zno. FT-IR analysis observed from the dried $\mathrm{ZnONPs}$ were recorded using the potassium bromide ( $\mathrm{KBr}$ is transparent in the $\mathrm{IR}$ region). This sample is compressed into a thin pellet using the mechanical press and characterized. Common region of IR spectroscopy is between $4000 \sim 400$ $\mathrm{cm}^{-1}$ because most organic compounds (natural products) and inorganic ions absorbs the radiation within this range ${ }^{22}$. SEM utilizes an electron microscope to produce the images of a sample with different magnifications in which samples scanned with the focused beam of electrons. It analyze the three-dimensional appearance that enables to understand the surface morphology of a sample. For SEM analysis, small amount of fine powder of ZnONPs was prepared as thin film and placed on mold by using carbon coated tape ${ }^{23}$. The surface morphology and quality of ZnONPs were investigated by the XRD. Conversion of the diffraction peaks to d-spacing allows to identify the nature of substance because each material has unique set of $d$-spacing. For typical powder XRD patterns, data is collected at $2 \theta$ from $5^{\circ}$ to $90^{\circ 24}$. Fine powered pale yellow ZnONPs were collected and analyzed using XRD. EDX helped to probe the composition of solid materials and to determine the chemical purity as well as elemental composition, density of the material, stoichiometry and can be used to estimate their relative abundance. This technique was carried out on Beta vulgaris mediated powdered ZnONPs.

\section{Anti-bacterial \& anti-fungal activities of Beta vulgaris mediated ZnONPs}

Beta vulgaris mediated ZnONPs was tested against the anti-bacterial and anti-fungal activity as per the Clinical Laboratory Standards Institute guidelines $(\mathrm{CLSI})^{25}$. The bacterial activity of Beta vulgaris mediated ZnONPs was screened by disc diffusion method against two bacteria species such as Escherichia coli (Gram-negative) and Staphylococcus aureus (Gram-positive). Likewise, two fungal strains, such as Candida albicans and Aspergillus flavus were used for anti-fungal activity of Beta vulgaris mediated ZnONPs.
Anti-Diabetic activity of Beta vulgaris mediated ZnO-Nps

Alpha-Amylase Inhibitory Assay

The alpha-amylase inhibitory assay was done by using the synthesized zinc nanoparticles (Anshuman Bhattacharya et al., 2016). Around 250 $\mu \mathrm{L}$ of $\mathrm{ZnONPs}(20 \mu \mathrm{g} / \mathrm{mL}-100 \mu \mathrm{g} / \mathrm{mL})$ was taken in a normal test tube to that, $250 \mu \mathrm{L}$ of $0.02 \mathrm{M}$ of sodium phosphate buffer containing the a-amylase was added. Whole solution was pre-incubated at $25^{\circ} \mathrm{C}$ for 10 mintues. After that, $250 \mu \mathrm{L}$ of $1 \%$ starch in $0.02 \mathrm{M}$ sodium phosphate buffer was added at the regular time intervals, later incubated at $25^{\circ} \mathrm{C}$ for 10 mintues. Addition of $500 \mu \mathrm{L}$ of dinitro salicylic acid (DNS) terminated the reactions then, the test tubes were incubated for 5 mintue. Then the cooled reaction mixture was again diluted by adding $5 \mathrm{~mL}$ of D.D water then the absorbance was measured at $540 \mathrm{~nm}$ using the spectrophotometer. In a same manner control was performed with the distilled water. The a-amylase inhibitory potential was calculated in terms percentage of inhibition.

\%Inhibition $=[($ Abs control-Abs ZnONPs $) / A b s$ control] x 100

\section{Alpha-Glucosidase Inhibitory Assay}

The anti-diabetic activity of ZnONPs on a-glucosidase was measured by using a-glucosidase assay by following Saccharomyces cerevisiae (Charushila et al., 2015). P-nitro phenyl glucopyranoside ( $p-N P G$ ) was initially prepared in the $20 \mathrm{mM}$ phosphate buffer solution which act as a substrate solution. $100 \mu \mathrm{L}$ of a-glucosidase was preincubated with $50 \mu \mathrm{L}$ of different concentrations (20 $\mu \mathrm{g} / \mathrm{mL}-100 \mu \mathrm{g} / \mathrm{mL}$ ) of ZnONPs for 10 minutes. To start the reaction $50 \mu \mathrm{L}$ of $3.0 \mathrm{mM}$ (pNPG) substrate was dissolved in $20 \mathrm{mM}$ phosphate buffer solution were added. Final reaction mixture was incubated at $37^{\circ} \mathrm{C}$ for 20 minutes then stopped by adding $2 \mathrm{~mL}$ of $0.1 \mathrm{M}$ $\mathrm{Na}_{2} \mathrm{CO}_{3}$. The inhibitory potential on a-glucosidase was determined by measuring the yellow-colored p-nitro phenol released from $\mathrm{p}-\mathrm{NPG}$ at $540 \mathrm{~nm}$.

In-vitro anticancer activity of ZnONps against breast cancer cell line (MCF7).

In-vitro anticancer Activity and cytotoxicity of ZnO nanoparticles

MCF-7 cells were trypsimized in 96 well plates, which contains the density of 4000 cells/well in $100 \mu \mathrm{L}$ and incubated for 24 hours. Then $0.1 \%$ of 
2X concentration of stock solution prepared in the DMEM medium influenced with $10 \%$ FCS added $(2000 \mu \mathrm{g} / \mathrm{mL}, 600 \mu \mathrm{g} / \mathrm{mL}, 200 \mu \mathrm{g} / \mathrm{mL}, 60 \mu \mathrm{g} / \mathrm{mL}$, $20 \mu \mathrm{g} / \mathrm{mL}, 6 \mu \mathrm{g} / \mathrm{mL}$ ) kept in incubation for 2 days to achieve the final concentration 1000, 300, 100, 30,10 and $3 \mu \mathrm{g} / \mathrm{mL}$. After incubation, the medium is washed with phosphate solution. After washing it is placed in a new medium MTT solution composed of 3-(4, 5-dimethylthiazol-2-yl)-2, 5-diphenyl tetrazolium bromide (MTT) at $5 \mathrm{mg} / \mathrm{mL}$ in $1 \mathrm{X}$ PBS, Which is incubated for 4 hours. After the incubation time, $1 \mathrm{~mL}$ of DMSO was added and the total viable cells were determined by measuring the absorbance at 540 $\mathrm{nm}$ by microplate reader. From the optical density/ absorbance values the percentage of growths or cell viability were calculated by the following formula:

Percentage growth $=100 \times\left[\left(\mathrm{T}^{-\mathrm{T}_{0}}\right) /\left(\mathrm{C}-\mathrm{T}_{0}\right)\right]$

Where,

T-Optical density of test,

C-The optical density of control,

$\mathrm{T}_{0}$-The optical density at zero time

\section{RESULTS AND DISCUSSION}

\section{UV-Visible spectroscopy}

The color change was observed after on addition of Beta vulgaris extract to the precursor zinc acetate solution. The color changes from dark reddish brown to dirty white precipitate (yellow coloration) which conformed the formation of ZnONPs. The optical property of formed zinc nanoparticles were observed by UV-Visible spectrophotometer ${ }^{26,27}$.One of the main factors involve in the nanoparticle synthesis is concertation of additives and precursor, which is studied in this research. The different concentrations of additive of 2, 4, 6, 8 and $10 \mathrm{~mL}$ (i.e. 1:4, 2:3, 3:2, 4:1 and 1:1) was adopted in this study and UV-spectral results observed that, at 3:2 ratio maximum absorbance was recorded at $291 \mathrm{~nm}$ (Fig. 1). Other major governing factor in green synthesis of nanoparticles is the $\mathrm{pH}$ and which was examined in this work (between 5 to10). 28 UV results revealed that, at the $\mathrm{pH}$ of 8 spectrum showed sharp intense peak at $269 \mathrm{~nm}$ (Fig. 2) ${ }^{29}$. This is because, weak bases absorbed at a high faster rate, that means the basic substances can't be ionized in basic medium. All the reaction mixtures (effect of concentration of precursor and $\mathrm{pH}$ ) of Beta vulgaris extract and zinc acetate was monitored using UV-Visible spectroscopy and their resulted absorptions range was close to the chemically prepared ZnONPs at 358nm. The slight variation in the values of absorbance are due to the changes in particle size.

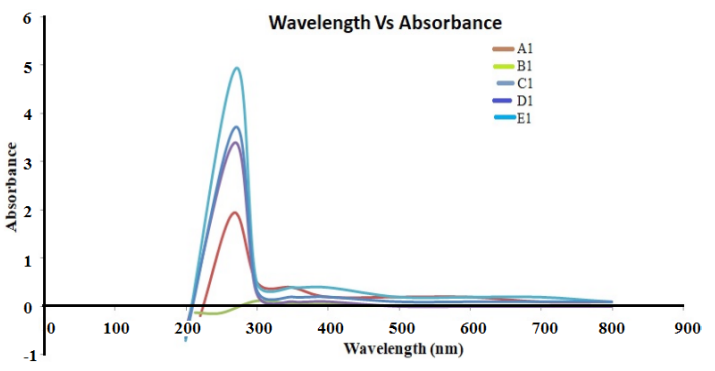

Fig. 1. Effect of concentration of reducing agent Beta vulgaris extract in the green synthesis of ZnONPs

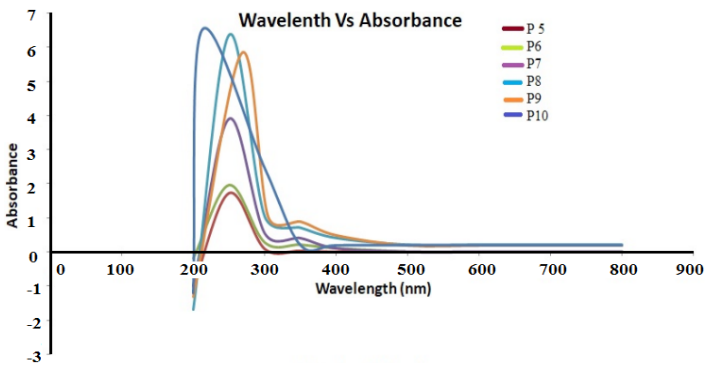

Fig. 2. Effect of $\mathrm{pH}$ in green synthesis of Beta vulgaris mediated ZnONPs

\section{FTIR Analysis}

The FT-IR spectra of Beta vulgar is aqueous extract was shown in the Fig. 3 which exhibits the frequencies at $3336 \mathrm{~cm}^{-1}$, $2113 \mathrm{~cm}^{-1}, 1637 \mathrm{~cm}^{-1}, 655 \mathrm{~cm}^{-1}$ and $607 \mathrm{~cm}^{-1}$ and are responsible for $\mathrm{OH}, \mathrm{C}=\mathrm{C}, \mathrm{C}-\mathrm{O}$ and alkyl halides of secondary metabolites such as flavonoids, phenolics, tannins, alkaloids, etc. Likewise, FT-IR results of ZnONPs reveals (Fig. 4) major absorption band at $3422 \mathrm{~cm}^{-1}$ indicate the presence of $\mathrm{O}-\mathrm{H}$ and $\mathrm{C}-\mathrm{H}$ stretching. $2129 \mathrm{~cm}^{-1}$ corresponds to stretching vibration of $\mathrm{C}=\mathrm{C}$ stretch of alkynes. $1351 \mathrm{~cm}^{-1}$ for aromatic amine and the peak at $1043 \mathrm{~cm}^{-1}$ resulted from C-N stretch of aliphatic amine. $1541 \mathrm{~cm}^{-1}$ and $1429.25 \mathrm{~cm}^{-1}$ corresponds to $\mathrm{C}=\mathrm{C}$ stretch in aromatic ring and $\mathrm{C}=\mathrm{O}$ stretch in polyphenols respectively. In the comparison of beet root extract IR with the synthesized ZnONPs, there is shift and elongations in the absorption band of formed ZnONPs that shows the bond formations of phytocompounds in the Beta vulgar is aqueous extract with the precursor, which leads to reduction of $\mathrm{Zn}^{2+}$ to $\mathrm{Zno}$ state of zinc ions. 


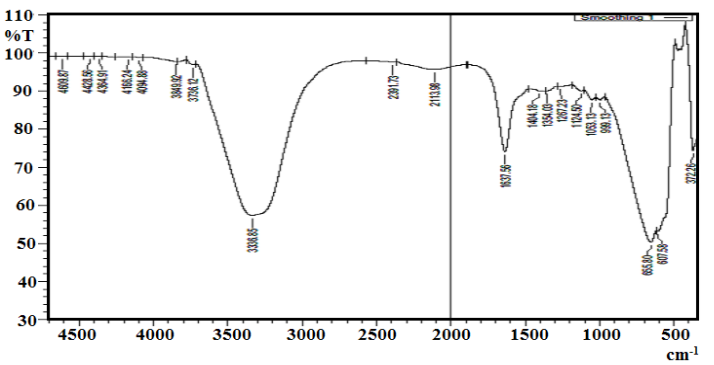

Fig. 3. FT-IR of Beta vulgaris aqueous extract

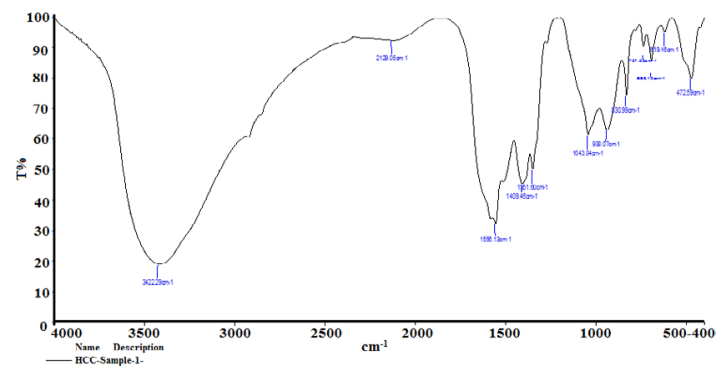

Fig. 4. FT-IR report of Beta vulgaris mediated ZnONPs

\section{X-Ray Diffraction (XRD) Analysis}

X-Ray Diffraction (XRD) spectroscopy was established to determine the crystalline nature of zinc nanoparticles. Washed and dried sample of ZnONPs was used for XRD analysis at the wavelength of $1.64056 \AA$ (Fig. 5). Obtained results confirming the presence of $\mathrm{ZnO}$ and the shape, structure were found from the resulted $X R D$ reports. The peaks appeared at $2 \theta$ value ranging from $31.9^{\circ}$, $33.29^{\circ}, 34.62^{\circ}, 36.43^{\circ}, 47.78^{\circ}$ and $56.81^{\circ}$ which are corresponds to the pure $\mathrm{ZnO} 30,31.2 \theta$ peaks values of Beta vulgaris mediated ZnONPs are in good agreement with the literature report (JCPDS 036-1451).The location peaks was compared to the literature values and the presence of zinc oxide particles was confirmed. The average particle size of nanoparticle is $16.2 \mathrm{~nm}$, and are calculated by using Debye-Scherrer's formula.

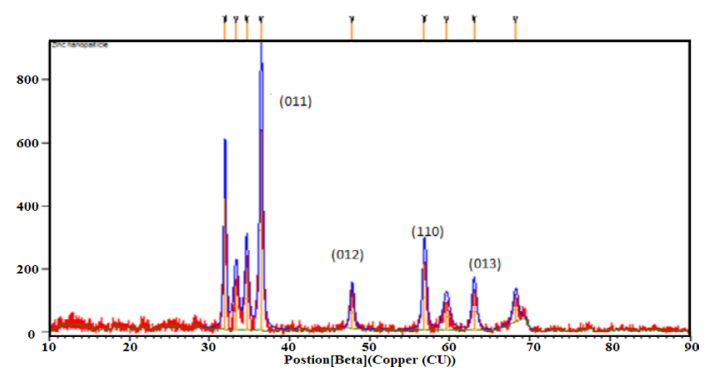

Fig. 5. XRD image of Beta vulgaris mediated ZnONPs

Energy Dispersive X-Ray Analysis (EDAX) of ZnONPs

Energy Dispersive X-Ray analysis of synthesized ZnONPs was examined to quantify the composition of metal and oxides present in it. The results (Fig. 6) showed that $55.63 \%$ of $\mathrm{Zn}, 32.53 \%$ of $\mathrm{O} 11.19 \%$ of carbon and $0.65 \%$ of Silicon were present in the resulted ZnONPs. The zinc metal and oxygen shows the maximum percentage of abundance in the synthesized nanoparticles ${ }^{32,33}$. EDAX showed the high intense peak of $\mathrm{ZnO}$ and low intense peak of Carbon and Silicon due to capping actions of biomolecules of plant extract in the $\mathrm{ZnO}$ nanoparticle formation.

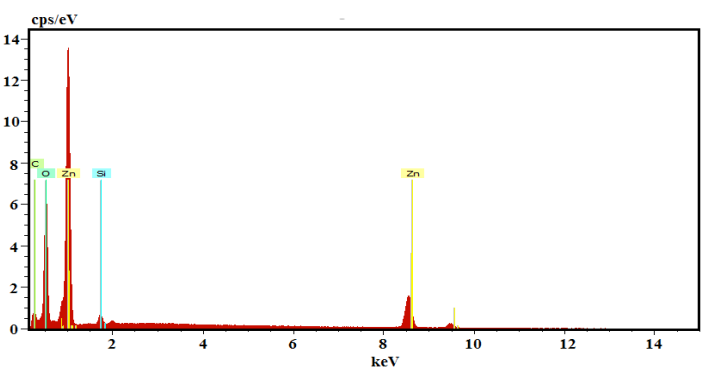

Fig. 6. EDAX spectrum of Beta vulgaris mediated ZnONPs Table 1: Percentage of elements in Beta vulgaris mediated

\begin{tabular}{ccc}
\hline S.No & Elements & Weight (\%) \\
\hline 1 & Zn & 55.63 \\
2 & $\mathrm{O}$ & 32.53 \\
3 & $\mathrm{C}$ & 11.19 \\
4 & $\mathrm{Si}$ & 0.65 \\
\hline
\end{tabular}

Scanning Electron microscopy of Beta vulgaris mediated ZnONPS

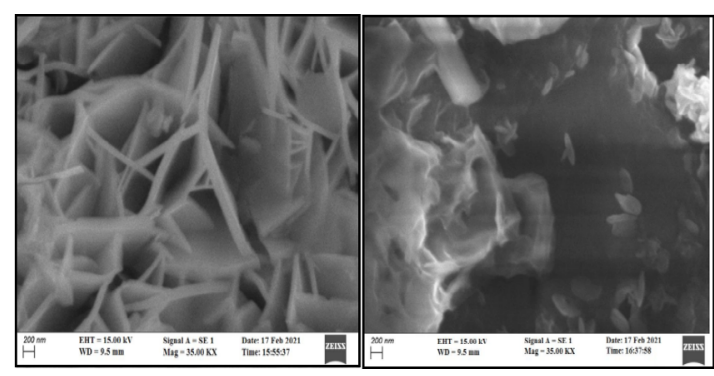

Fig. 7. EDAX spectrum of Beta vulgaris mediated ZnONPs

SEM analysis is used to visualize the shape and size of the Beta vulgaris extract mediated zinc oxide nanoparticles. The different magnification ranges of ZnONPs from $1 \mu \mathrm{m}-200 \mathrm{~nm}$ were shown in Fig. 7 which shows the poly dispersed structure. ${ }^{34,35}$

\section{Antimicrobial activity of Beta vulgaris mediated ZnONPs}

The antibacterial effect of $\mathrm{ZnO}$ nanoparticles shows the maximum zone inhibition against a Gram-negative bacteria-Escherichia coli (MTCC 
25922) while compared to Gram-positive bacteria Staphylococcus aureus (MTCC 25923). The data obtained from the Table 2 and Fig. 8 , it shows well bactericidal efficiency at higher concentration. ${ }^{33}$ Bacteria generally made up of cell wall, cell membrane which is consists of amino acids and sugars. Gram-positive bacteria have one membrane with multilayer of peptidoglycan polymer and a very thick cell wall whereas Gram-negative bacteria consists of two membrane with very thin polymer. The small sized particles are well penetrated in to the bacterial cell and shows the better inhibition effect compared to gram positive bacteria ${ }^{43}$. The different in activities is due to variation in particle size and phytochemicals present in the plant extract. ${ }^{32}$ Generally the synthesized nanoparticles carry a negative charge which strongly binds with the negatively charged microorganism due to this excitation the concentration of oxygen increases. Singlet oxygen are more reactive and enhance the antibacterial activity. ${ }^{45}$

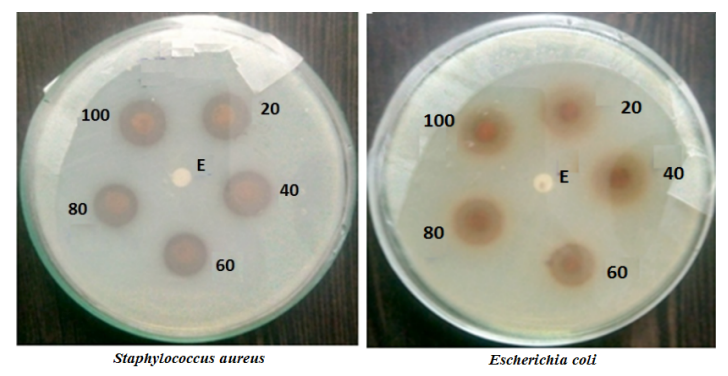

Fig. 8. Antibacterial activity of Beta vulgaris mediated ZnONPs

Table 2: Antibacterial activity of Beta vulgaris mediated ZnONPs

\begin{tabular}{|c|c|c|c|}
\hline \multirow[t]{2}{*}{ Samples } & \multirow[t]{2}{*}{$\begin{array}{l}\text { Concentrations } \\
(\mu \mathrm{g} / \mathrm{mL})\end{array}$} & \multicolumn{2}{|c|}{$\begin{array}{c}\text { Organisms/Zone of inhibition }(\mathrm{mm}) \\
\text { SS }\end{array}$} \\
\hline & & Escherichia coli & Staphylococcus aureus \\
\hline \multirow[t]{5}{*}{ SS } & 20 & 5 & 4 \\
\hline & 40 & 6 & 5 \\
\hline & 60 & 7 & 6 \\
\hline & 80 & 8 & 7 \\
\hline & 100 & 9 & 8 \\
\hline Ethanol & $10 \mu \mathrm{l} / \mathrm{disc}$ & 0 & 0 \\
\hline
\end{tabular}

Antifungal activity of Beta vulgaris mediated ZnONPs

The cell wall of fungal strains, such as Candida albicans and Aspergillus flavus is less structured but allows the fungus breakage of the immune system converting Candida albicans as a pathogen. The results were compared with the report work. The prepared $\mathrm{ZnO}$ nanoparticles shows better results, very active only at higher concentration. ${ }^{36}$ From the Table 3 the results showed that, the inhibitory potential of ZnONPs is increased (the zone of inhibition) with increase of concentration. The Candida albicans (MTCC 282) shows the better inhibition on comparing with Aspergillus flavus (MTCC 227). ${ }^{37,38}$ The good inhibitory effect of ZnONPs against Candida albicans is become most important opportunistic medical pathogenic fungus.

Table 3: Antifungal activity of Beta vulgaris mediated ZnONPs

\begin{tabular}{cccc}
\hline Samples & $\begin{array}{c}\text { Concentrations } \\
(\mu \mathrm{g} / \mathrm{mL})\end{array}$ & \multicolumn{2}{c}{$\begin{array}{c}\text { Organisms/Zone of inhibition (mm) } \\
\text { SS }\end{array}$} \\
& Candida albicans & Aspergillus flavus \\
\hline \multirow{2}{*}{ SS } & 20 & 3 & 1 \\
& 40 & 4 & 1 \\
& 60 & 5 & 1 \\
& 80 & 6 & 1 \\
Ethanol & 100 & 7 & 2 \\
\hline
\end{tabular}

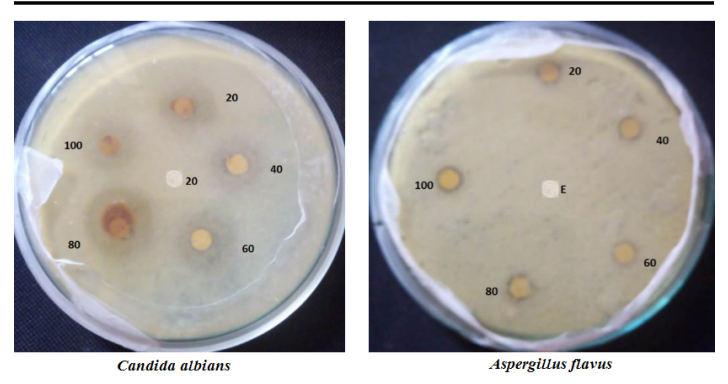

Fig. 9. Antifungal activity of Beta vulgaris mediated ZnONPs

Antidiabetic activity of Beta vulgaris mediated ZnONPs by alpha amylase inhibitory method

The results of antidiabetic activity of Beta vulgaris mediated ZnONPs and standard acarbose by alpha amylase inhibitory method was shown in Fig. 10 and 11. From the Table 4 it is understood that, when increase the concentration of ZnONPs the percentage of inhibition of alpha amylase was increased. At $100 \mu \mathrm{g} / \mathrm{mL}$ concentration the Beta vulgaris mediated ZnONPs and standard acarbose shows the $79.87 \%$ and $86.21 \%$ of antidiabetic activity on alpha amylase method. $\mathrm{ZnO}$ nanoparticles reduced by Beta vulgar is extract shows better effect of about $79 \%$ of inhibition which can act as an alternative anti diabetic agent. Similar reports was obtained in the other research findings, Dilaveez Rehana et al., ${ }^{39}$ and Viswanathan Vinotha et al., ${ }^{40}$ studied the anti-diabetic activities of $\mathrm{ZnO}$ nanoparticles and $\mathrm{Ci}-\mathrm{ZnO} \mathrm{Nps}$ by alpha amylase inhibitory method which possess $89 \%$ and $74 \%$ of inhibition potentials respectively. 


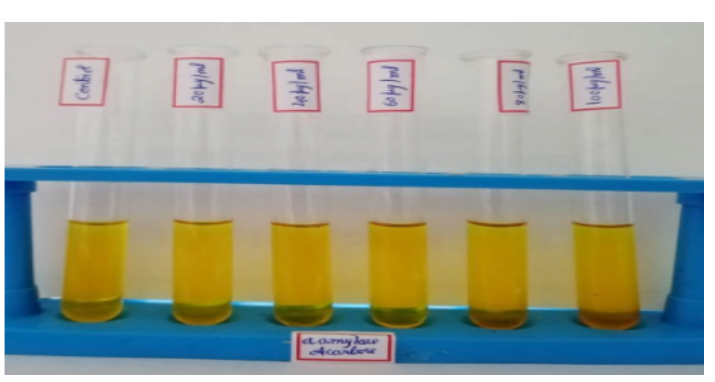

Fig. 10. Antidiabetic activity of standard acarbose by alpha amylase inhibitory method

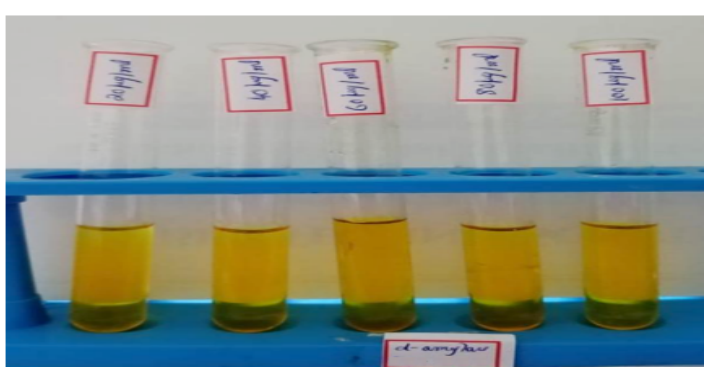

Fig.11. Antidiabetic activity of Beta vulgaris mediated ZnONPs by alpha amylase inhibitory method

Table 4: In vitro antidiabetic activity of Beta vulgaris mediated ZnONPs using alpha amylase method in comparison with standard drug acarbose

\begin{tabular}{cccc}
\hline S.No & Concentrations & \multicolumn{2}{c}{ Alpha amylase (\%) } \\
& & Zinc-NP & Acarbose \\
\hline 1 & $20(\mu \mathrm{g} / \mathrm{mL})$ & 58.84 & 67.90 \\
2 & $40(\mu \mathrm{g} / \mathrm{mL})$ & 62.36 & 73.53 \\
3 & $60(\mu \mathrm{g} / \mathrm{mL})$ & 68.60 & 78.46 \\
4 & $80(\mu \mathrm{g} / \mathrm{mL})$ & 74.33 & 82.69 \\
5 & $100(\mu \mathrm{g} / \mathrm{mL})$ & 79.87 & 86.21 \\
\hline
\end{tabular}

Antidiabetic activity of Beta vulgaris mediated ZnONPs by alpha glucosidase inhibitory method

The In-vitro antidiabetic activity results of Beta vulgar is mediated ZnONPs and standard drug acarbose using alpha glycosidase method is displayed in Fig. 12 \& 13. Summarized results was shown in Table 5 which explains that, at $100 \mu \mathrm{g} /$ $\mathrm{ml}$ concentration ZnONPs and standard acarbose shows the inhibition percentages of 76.45 and 86.45 respectively. Dilaveez Rehana et al., ${ }^{39}$ and Viswanathan vinotha et al., ${ }^{40}$ studied the anti-diabetic activities of $\mathrm{ZnO}$ nanoparticles and $\mathrm{Ci}-\mathrm{ZnO} \mathrm{Nps}$ by alpha glycosidase inhibitory method which possess $96 \%$ and $82 \%$ of inhibition effects respectively.

From the Table 4 \& 5, the green synthesized zinc nanoparticles shows a good inhibitory effect against the both the methods. The values of $\mathrm{Zn}$ nanoparticles are close to the value of control acarbose which means Beta vulgaris mediated ZnONPs have the significant antidiabetic activity. From the literature survey ${ }^{41,42}$ suggested less degradation of insulin by the synthesized nanoparticles. The a-glucose and a-amylase involved in the inhibition of metabolic activity along with the insulin secretion from the pancreatic islets and send message to the brain. In the absence of insulin secretion that leads to diabetics and these enzymes remains in the metabolic activity only, which is not recognized by the brain. To overcome this problem the green synthesized $\mathrm{ZnO}$ nanoparticles play important role in the inhibition of the enzymes activity and further metabolic activity can be controlled as a result the breakdown of glucose and carbohydrates will be reduced. From the above data shows the improved activity of the synthesized nanoparticles which is clearly shown in the closer values to the control. Increase in the concentration increases the anti-diabetic activity.

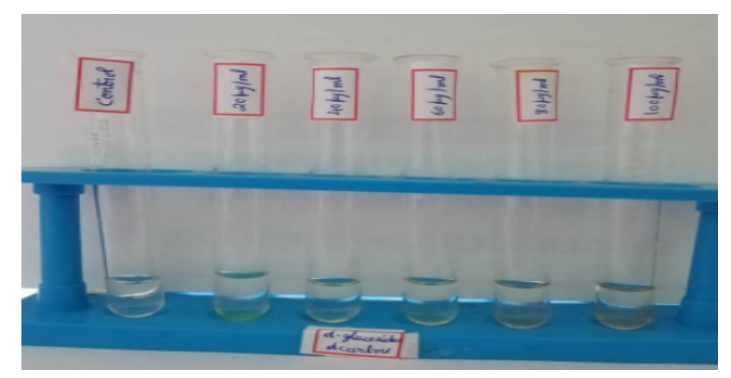

Fig. 12. Antidiabetic activity of standard acabose by alpha glucosidase inhibitory method

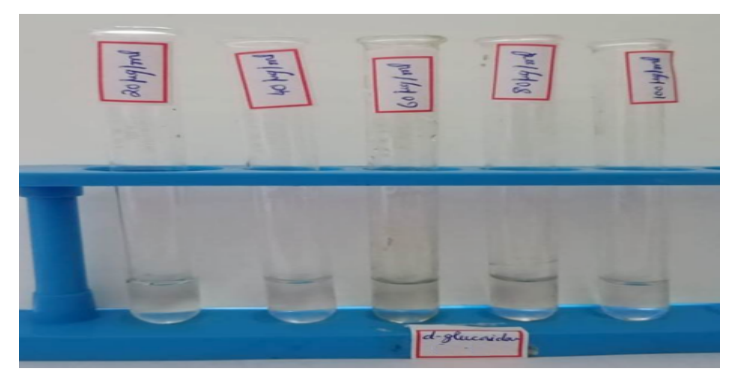

Fig. 13. Antidiabetic activity of Beta vulgaris mediated ZnONPs by alpha glucosidase inhibitory method

Table 5: In vitro antidiabetic activity of Beta vulgaris mediated ZnONPs using alpha glycosidase method in comparison with standard drug acarbose

\begin{tabular}{cccc}
\hline S.No & Concentrations & \multicolumn{2}{c}{ Alpha glycosidase (\%) } \\
& & Zinc-NP & Acarbose \\
\hline 1 & $20(\mu \mathrm{g} / \mathrm{mL})$ & 49.18 & 74.63 \\
2 & $40(\mu \mathrm{g} / \mathrm{mL})$ & 60.09 & 78.27 \\
3 & $60(\mu \mathrm{g} / \mathrm{mL})$ & 66.45 & 81 \\
4 & $80(\mu \mathrm{g} / \mathrm{mL})$ & 73.72 & 83.72 \\
5 & $100(\mu \mathrm{g} / \mathrm{mL})$ & 76.45 & 86.45 \\
\hline
\end{tabular}


Anti-breast cancer of Beta vulgaris mediated ZnONPs by MTT assay (MCF7 cell line)

Anticancer activity of $\mathrm{ZnO}$ nanoparticles result shows the exposure of MCF-7 cells to $\mathrm{ZnO}$ nanoparticles at the various concentration for $72 \mathrm{~h}$, significantlythat reduce the cell viability in a concentration dependent manner. As the concentraion increases the cell viability decreases. For the synthesised compound Zno nanoparticles 3-304 $\mu \mathrm{g} / \mathrm{mL}$ concentration cell viability percentage value decreased from 102.9-23.6 for MCF-7. For $\mathrm{ZnO}$ nanoparticles the concentration cell viability decreased to $27.9 \%$ whereas with other report appears up to $55.6 \%$ for commercial $\mathrm{ZnO}^{43,44}$. MCF-\& cells were exposed to $\mathrm{ZnO}$ nanoparticles and $50 \%$ of its toxicity was reduced at very low concentration from, the studies $\mathrm{ZnO}$ nanoparticles selectively target and kills the cancer cells so this green synthesized nanoparticles show a promising anticancer agent $\mathrm{IC}_{50}$ value for $\mathrm{ZnO}$ are 40 and
$50 \mu \mathrm{g} / \mathrm{mL}^{45}, \mathrm{IC}_{50}$ value of human colon anorectal carcinoma cells shows $17.12 \mu \mathrm{g} / \mathrm{mL}^{46}$, Breast MCF7 of $\mathrm{ZnO} \mathrm{Q}$-dots as a potent therapeutic for In vitro cytotoxicity shows $41 \mu \mathrm{g} / \mathrm{mL}^{47}$. The present study revealed that the Zinc-NP showing comparatively strong cytotoxic effect with the calculated $I C_{50}$ value of $35.4 \mu \mathrm{g} / \mathrm{mL}$ on MCF-7 cell line.

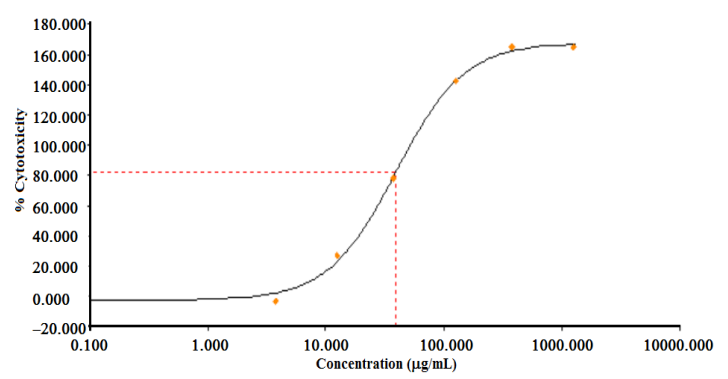

Fig. 14. Anticancer activity results of Beta vulgaris mediated ZnONPs on MCF7 cell line

\section{Beta vulgaris Mediated ZnONPs Cytotoxic Effect} On MCF-7 Cell Line

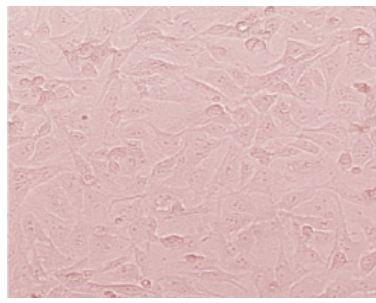

Fig. 15a. Control cell

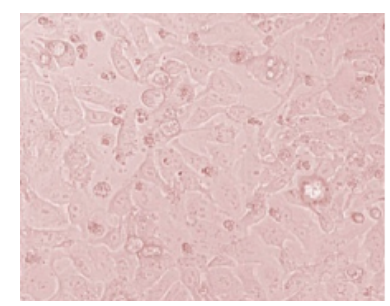

Fig. $15 \mathrm{~d} .30 \mu \mathrm{g} / \mathrm{mL}$

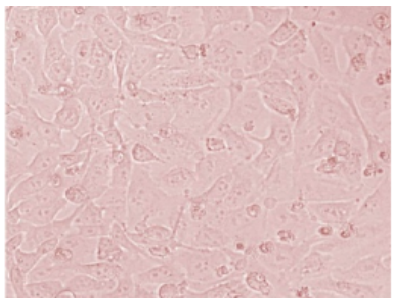

Fig. $15 \mathrm{~b} .3 \mu \mathrm{g} / \mathrm{mL}$

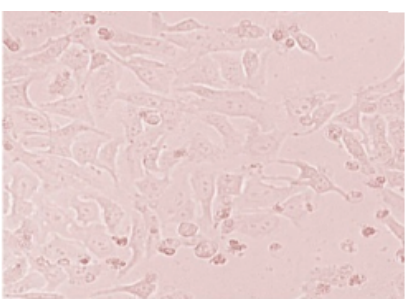

Fig. $15 \mathrm{e} .100 \mu \mathrm{g} / \mathrm{mL}$

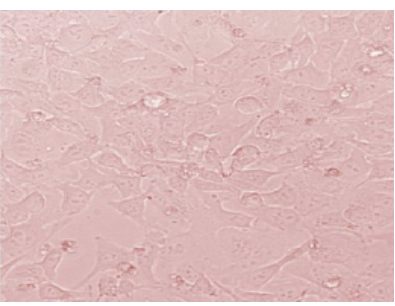

Fig. $15 \mathrm{c} .10 \mu \mathrm{g} / \mathrm{mL}$

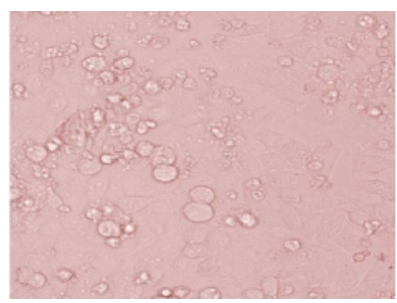

Fig. $15 f .300 \mu \mathrm{g} / \mathrm{mL}$

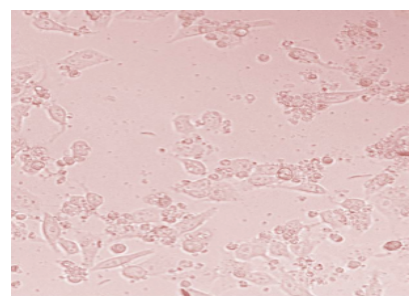

Fig. $15 \mathrm{~g} .1000 \mu \mathrm{g} / \mathrm{mL}$

Fig. 15a-15g. Control cells and treated cells images of anticancer activity of Beta vulgaris mediated ZnONPs on MCF7 cell line

\section{CONCLUSION}

The present study shows the biological synthesis route of $\mathrm{ZnO}-\mathrm{Nps}$ using Beta vulgaris extract. The green synthesis provides an environmental friendly, simple and efficient method for the synthesis of nanoparticles. XRD analyse the particle size of prepared $\mathrm{ZnO} \mathrm{Nps}$ is about $16.2 \mathrm{~nm}$ which are calculated by using scherrer's formula. EDAXresults shows the percentage of zinc as $55.63 \%$ 
and oxygen $32.53 \%$ which shows the presence of $\mathrm{Zn}$ and oxygen in the synthesised $\mathrm{ZnO}$ Nps. The poly dispersed shape of the synthesised Nanoparticle is confirmed by SEM, The green synthesized nanoparticle was further studied to understand its antimicrobial and antifungal activity. The antifungal agents helps to overcome the obstacles in the fungal disease posed by development of resistance to conventional fungicides. The $\mathrm{ZnO} \mathrm{Nps}$ are naturally stabilised by their biological compounds flavanoids and polyphenols, which can inhibit a-amylase and a-glucosidase. The bio active compounds with $\mathrm{ZnO}$ Nps have greater potential against antidiabetic activity. The present study also intends to screen the a-amylase and a-glucosidase activity of green synthesised nanoparticles, which minimize the toxicity and side effects of the inhibitors used to control diabetes. The ZnONps are showing cytotoxic effect on the tested cell line. The $\mathrm{IC}_{50}$ value for the Zinc-NP, $35.4 \mu \mathrm{g} / \mathrm{mL}$ shows the better anti-cancer activity. Beta vulgaris mediated green synthesized ZnONPs shows a promising antibacterial, antifungal, antidiabetic and anticancer agents and it can further confirmed by In-vivo animal models in future.

\section{ACKNOWLEDGMENT}

This research did not receive any specific grant from funding agencies in the public, commercial, or not-for-profit sectors.

\section{Conflicts of interest}

The authors have declared no conflicts of interest.

\section{REFERENCES}

1. Sivasankarapillai, V. S.; Jose, J.; Shanavas, M. S.; Marathakam, A.; Uddin, M. S., Mathew, B. Silicon quantum dots: Promising theranostic probes for the future. Curr. Drug Targets., 2019, 20(12), 1255-1263.

2. Khanna, V.K. Nanoparticle - based Sensors. Defence. Sci. J., 2008, 58(5), 608-616.

3. Fahimmunisha, B. A.; Ishwarya, R.; AISalhi, M. S.; Devanesan, S.; Govindarajan, M.; Vaseeharan, B. Green fabrication, characterization and antibacterial potential of zinc oxide nanoparticles using Aloe socotrina leaf extract: A novel drug delivery approach. J. Drug Deliv. Sci. Technol., 2020, 55.

4. Lingaraju,K.;Raja Naika,H.; Manjunath,K.; Basavaraj, R. B.; Nagabhushana,H., Nagaraju, G.;Suresh, D.Biogenic synthesis of zinc oxide nanoparticles using Ruta graveolens (L.) and their antibacterial and antioxidant activities. Appl. Nanosci., 2016, 6, 703-710.

5. Hwa, K.Y.; Subramani,B. Synthesis of zinc oxide nanoparticles on graphene-carbon nanotube hybrid for glucose biosensor applications. Biosens. Bioelectron., 2014, 62(15), 127-133.

6. Singh,J.; Dutta,T.; Kim, K.H.; Rawat,M.; Samddar, P.; Kumar,P. Green Synthesis of metals and their oxide nanoparticles: applications for environmental remediation. J. Nanobiotechnology., 2018, 16, 84.

7. Ramesh,P.;Rajendran, A.;Sundaram,M.
Green syntheis of zinc oxide nanoparticles using flower extract cassia auriculata.J. Nanosci. Nanotechnol., 2014, 2(1), 41-45.

8. Sangeetha,G.; Rajeshwari, S.; Rajendran,V. Green synthesis of zinc oxide nanoparticles by aloe barbadensis miller leaf extract: Structure and optical properties. Mater. Res. Bull., 2011, 46(12), 2560-2566.

9. Vidya,C.; Hirematha, S.; Chandraprabha,M. N.; Antonyraja, M. A. L.; Gopala ,I. V.; Jaina, A.; Bansala,K.Green synthesis of $\mathrm{ZnO}$ nanoparticles by Calotropis gigantean. Int. J. Curr. Engr. Technol., 2013, 1(1), 118-120.

10. Yedurkar,S.; Maurya,C.; Mahanwar,P. Biosynthesis of zinc oxide nanoparticles using ixora coccinea leaf extract-a green approach. Open J. Syn. Theor. Appln., 2016, 5(1), 1-14.

11. Sharmila Devi, R.; Gayathri,R.Green Synthesis of Zinc Oxide Nanoparticles by using Hibiscus rosa-sinensis. Int. J. Curr. Engr. Technol., 2014, 4(4), 2444-2446.

12. Udayasoorian ,C.; Vinoth Kumar ,K.; Jayabalakrishnan, R. M.Extracellular synthesis of silver nanoparticles using leaf extract of Cassia auriculata. Dig. J. Nanometer. Biostruct, 2011, 6(1), 279-283.

13. Singh,A.; Jain,D.; Upadhyay,M.K.; Khandelwal, N; Verma, H. N.Green Synthesis of Silver Nanoparticles Using Argemone Mexicana Leaf Extract And Evaluation of Their Antimicrobial Activities. Dig. J. Nanometer. Biostruct., 2010, 5(2), 483-489. 
14. Luque,P.A.; Nava,O.; Soto-Robles,C.A.; Vilchis-Nestor,A.R.; Garrafa-Galvez,H.E.; Castro-Beltran,A. Effects of Daucus carota extract used in green synthesis of zinc oxide nanoparticles. J. Mater. Sci. Mater. Electron. 2018, 29(20), 17638-17643.

15. Baiao,D.S.; Silva,D.V.T.; Aguila, E. M.; Paschoalin,V. M. F.Nutritional, Bioactive and Physicochemical Characteristics of Different Beetroot Formulations. Food Addit., 2017, 2, 21-43.

16. Singh, B.; Hathan,B.S.Chemical composition, functional properties and processing of beetroot-a review. Int. J. Sci. Eng. Res., 2014, 5(1), 679-684.

17. Georgiev,V.G.;Weber,J.;Kneschke,E.M.; Denev,P.N.; Bley,T.; Pavlov,A.I.Antioxidant activity and phenolic content of betalain extracts from intact plants and hairy root cultures of the red beetroot Beta vulgaris cv. Detroit dark red. Plant Foods Hum. Nutr., 2010, 65(2), 105-111.

18. Clifford,T.; Howatson,G.; West,D.; Stevenson, $E$. The potential benefits of red beetroot supplementation in health and disease. Nutrients., 2015, 7(4), 2801-2822.

19. Romero, L. P.; Luque,P.A.; Robles,C.A.; Nava,O.; Vilchis-Nestor,A.R.; Carrillo,V.W. B.; Martínez-Ramírez,C.E.; Méndez,J.R.C.; Palacios,J.A.; Leal Avila, M.A.; AlmanzaReyes,H.; Synthesis, characterization and cytotoxicity of zinc oxide nanoparticles by green synthesis method. J. Drug. Deliv. Sci. Technol., 2020, 60.

20. Bhatt, M.;Ayyalasomayajula, K.R.; Yalavarthy, P. K.Generalized Beer-Lambert Model for Near Infrared Light Propagation in Thick Biological Tissues. J. Biomed. Opt., 2016, 21 (7), 076012-076023.

21. Lubna R. Shah.; Weigang Wang.; Hao Zhu, Bakhtyar Ali.; Song,Y. Q.; Zhang,H. W.; Shah, S. I.; Xiao,J. Q.Role of dopant, defect, and host oxide in the observed room temperature ferromagnetism: Co-ZnO versus $\mathrm{Co}-\mathrm{CeO}_{2}$. J. Appl. Phys., 2009, 105, 07C515.

22. Movasaghi,Z.; Rehman, S.; Rehman,I.Fourier Transform Infrared (FTIR) Spectroscopy of Biological Tissues. Appl. Spectrosc. Rev., 2008, 43(1), 134-179.

23. Lemine,O.M.Microstructural characterisation of $\mathrm{a}-\mathrm{Fe}_{2} \mathrm{O}_{3}$ nanoparticles using, XRD line profiles analysis, FE-SEM and FT-IR, Superlattices microstruct., 2009, 45(6), 576-582.

24. Pomies,M. P.; Morin, G.; Vignaud,C. XRD study of the goethite-hematite transformation: Application to the identification of heated prehistoric pigments. Eur. J. Solid State Inorg. Chem., 1998, 35, 9-25.

25. Hsueh, P. R.; Ko,W. C.; Wu, J.J.; Lu, J.J.; Wang, F.D.; Wu, H.Y.; Wu,T. L.; Teng, L. J. Consensus Statement on the Adherence to Clinical and Laboratory Standards Institute (CLSI) Antimicrobial Susceptibility Testing Guidelines (CLSI-2010 and CLSI-2010-update) for Enterobacteriaceae in Clinical Microbiology Laboratories in Taiwan. J. Microbiol. Immunol. Infect., 2010, 43(5), 452-455.

26. Saputra, S.; Yulizar, Y.Biosynthesis and characterization of $\mathrm{ZnO}$ nanoparticles using the aqueous leaf extract of Imperata cylindrica L. IOP Conf. Ser.: Mater. Sci. Eng., 2017, 188, 012004.

27. Jamdagni, P.; Khatri, P.; Rana,J.S. Green synthesis of zinc oxide nanoparticles using flower extract of Nyctanthes arbor-tristis and their antifungal activity. J. King Saud Univ. Sci., 2018, 30(2), 168-175.

28. Chikkanna, M. M.; Neelagund, S. E.; Rajashekarappa, K. K. Green synthesis of zinc oxide nanoparticles (ZnONPs) and their biological activity. SNAppl. Sci., 2019, 1, 117.

29. Aminuzzaman,M.;Ying,L.P.;Goh, W. S.; Watanabe, A.; Green synthesis of zinc oxide nanoparticles using aqueous extract of Garcinia mangostana fruit pericarp and their photocatalytic activity. Bull. Mater. Sci., 2018, 41(2), 1-10.

30. Upadhyaya, H.; Shome, S.; Sarma,R.; Tewari, S.; Bhattacharya, M. K.;Panda, S.K.; Green synthesis, characterization and antibacterial activity of $\mathrm{ZnO}$ nanoparticles. Am. J. Plant Sci., 2018, 9(6), 1279-1291.

31. Noorjahan, C. M.; Shahina, S. K. J.; Deepika, T.; Rafiq,S. Green synthesis and characterization of zinc oxide nanoparticles from Neem (Azadirachta indicia). Int. J. Sci. Eng. Technol. Res., 2015, 4(30), 5751-5753.

32. Pirtarighat,S.; Ghannadnia, M.; Baghshahi,S. Green synthesis of silver nanoparticles using the plant extract of Salvia spinosa grown in vitro and their antibacterial activity assessment.J. Nanostrct. Chem., 2019, 9, 1-9. 
33. Dhabi, N.A.A.; Arasu,M.V. EnvironmentallyFriendly Green Approach for the Production of Zinc Oxide Nanoparticles and Their AntiFungal, Ovicidal, and Larvicidal Properties. Nanomaterials., 2018, 8(500), 1-13.

34. Anshuman Bhattacharya.; Raja Chakraverty. The pharmacological properties of Annona squamosa Linn: A Review. Int. J Pharm. Eng., 2016, 4(2), 693-699.

35. Charushila N. Hajare.; Farida R. Inamdar.; Reshma V. Patil.; Chidanand S. Shete.; Suryakant S. Wadkar.; Kumar S. Patil.; Jai S. Ghosh.; Antibacterial Activity of the Leaves of Bougainvillea spectabilis against $\mathrm{E}$. coli NCIM 2832 and M. aureus NCIM 5021. Int. J. Pharm. Sci. Rev. Res., 2015, 34(1), 194-196.

36. Ryo suke.Tanino.; Yoshihiro Amano.; Xuexia Tong.; Rong Sun.; Yukari Tsubata.; Mamoru Harada.; Yasuhisa Fujita.; Takeshi Isobe. Anticancer Activity of $\mathrm{ZnO}$ Nanoparticles against Human Small-Cell Lung Cancer in an Orthotopic Mouse Model. Mol. Cancer. Ther., 2020, 19(2), 502-512.

37. Selvakumari D.; Deepa,R.; Mahalakshmi Velrajan.; Subashini pattappa.; Lakshminarayan, N. Anti Cancer Activity of $\mathrm{ZnO}$ Nanoparticles on MCF7 (Breast Cancer Cell) and A549 (Lung Cancer Cell). ARPN J. Eng. Appl. Sci., 2015, 10(12), 5418-5421.

38. Elsayed, E. A.; Moussa, S.A.; El-Enhasy, H. A.; Wadaan, M. A.Anticancer Potentials of Zinc Oxide Nanoparticles against Liver and Breast Cancer Cell Lines. J. Sci. Ind. Res., 2020, 79, 56-59.

39. Dilaveez Rehana.; Mahendiran, D.; Senthil kumar, R.; Kalilur rahiman, A. In-vitro antioxidant and antidiabetic activities of zinc oxide nanoparticles synthesized using different plant extracts. Bioprocess Biosyst Eng., 2017, 40(6), 943-957.

40. Viswanathan vinotha.; Baskaralingam Vaseeharan.; Viswanathan vinotha.; Arokiadhaslswarya.; Rajagopalan Thaya.; Marimuthu govindarajan.; Naiyf S. Alharbi.; Shine Kadaikunnan.; Jamal M. Khaled.; Mohammed N. Al-Anbr.; Baskaralingam Vaseeharan. Synthesis of $\mathrm{ZnO}$ nanoparticles using insulin-rich leaf extract: Anti-diabetic, antibiofilm and anti-oxidant properties. J. Photochem. Photobiol. B., 2019, 197, 111541.

41. Jamuna Bai Aswathanarayan.; Ravishankar Rai Vittai.; Uma Shankar Muddegowda. Anticancer activity of metal nanoparticles and their peptide conjugates against human colon adenorectal carcinoma cells. Artif. Cell Nanomed. B., 2018, 46(7), 1444-1451.

42. Zahra Fakhroueian.; Rouhollah vahabpour.; Mehdi assmar.; Alireza massiha.; Afshin zahedi.; Pegah esmaeilzadeh.; Fatemeh katouzian.; Sara rezaei.; Peyman keyhanvar.; Alireza mozafari dehshiri. ZnO Q-dots as a potent therapeutic nanomedicine for In-vitro cytotoxicity evaluation of mouth KB44, breast MCF7, colon HT29 and HeLa cancer cell lines, mouse ear swelling tests In-vivo and its side effects using the animal model. Artif Cell Nanomed B., 2018, 46(2), 96-111.

43. Amna Sirelkhatim.; Shahrom Mahmud.; Azman Seeni.; Noor Haida Mohamad Kaus.; Ling Chuo Ann.; Siti Khadijah Mohd Bakhori.; Habsah Hasan.; Dasmawati Mohamad. Review on Zinc Oxide Nanoparticles: Antibacterial Activity and Toxicity Mechanism, Nanomicro Lett., 2015, 7(3), 219-242.

44. Waseem ahmad.; Divya Kalra. Green synthesis, characterization and anti microbial activities of $\mathrm{ZnO}$ nanoparticles using Euphorbia hirta leaf extract. J. King Saud Univ. Sci., 2020, 32(4), 2358-2364.

45. Kumaresan, S.; Haja Hameed,A. S.; Karthikeyan, C.; Senthil Kumar, V. Effect of $\mathrm{Mg}^{2+}, \mathrm{Ca}^{2+}, \mathrm{Sr}^{2+}$ and $\mathrm{Ba}^{2+}$ metal ions on the antifungal activity of $\mathrm{ZnO}$ nanoparticles tested against Candida albicans. Mater. Sci. Eng. C., 2015, 52, 171-177.

46. Abdolhossien Miri.;Nafiseh Mahdinejad.; Omolbanin Ebrahimy.; Mehrdad Khatami.; Mina Sarani. Zinc oxide nanoparticles: Biosynthesis, characterization, antifungal and cytotoxic activity. Mater. Sci. Eng. C., 2019, 104, 109981.

47. Geetha,M.S.; Nagabhushana, H.; Shivananjaiah, H.N. Green mediated synthesis and characterization of $\mathrm{ZnO}$ nanoparticles using Euphorbia Jatropa latex as reducing agent. J. Sci-Adv. Mater. Dev., 2016, 1, 301-310. 